\title{
A Creative Research Process for a Modern African Graphic Design Identity; The Case of Ivory Coast
}

\author{
Adam Yeo ${ }^{\circledR}$, Fang Cao \\ Department of Design, Nanjing University of the Arts, Nanjing, China \\ Email: yeo_adam2007@yahoo.fr, ccaofang@163.com
}

How to cite this paper: Yeo, A., \& Cao, F. (2021). A Creative Research Process for a Modern African Graphic Design Identity; The Case of Ivory Coast. Art and Design Review, 9, 210-231.

https://doi.org/10.4236/adr.2021.92017

Received: April 20, 2021

Accepted: May 23, 2021

Published: May 26, 2021

Copyright $\odot 2021$ by author(s) and Scientific Research Publishing Inc. This work is licensed under the Creative Commons Attribution International License (CC BY 4.0).

http://creativecommons.org/licenses/by/4.0/

\begin{abstract}
This study seeks to define a research method in graphic design that would result in a new graphic design with an African, identity, (particularly an Ivorian idendity). In this study we used a descriptive research method with the purpose of demonstrating how to create a graphic design that reflects the national spirit and identity. This paper first analyzes the concepts of culture and cultural identity as a basis for creating this African identity in modern graphic design, then explores the African visual language as a means to enrich this new African graphic design, and finally analyzes the application of traditional graphic symbols and cultural concepts in graphic design based on a comprehensive understanding of these traditional elements important in development of an African design style (the case of Ivory Coast). Based on data collected, this research concluded that in modern graphic design, the use of elements from the culture of a country, such as cultural concepts, graphic symbols, traditional colors, and other traditional art components is an excellent way to create new features. It allows to bring out the national identity in our work through development of creativity that relies precisely on the elements of this culture. This practice is common today. Concisely it contributes to enrich and developing modern graphic design.
\end{abstract}

\section{Keywords}

African Graphic Design, Identity, Cultural, Creativity, Graphic Symbols

\section{Introduction}

Cultural identity, modernity, tradition, creativity, and innovation have been 
the focus of design discussions in recent years. In the field of modern graphic design, the current trend is to create national peculiarities and integrate their characteristics into the international design level to convey the national spirit in design works. In graphic design, the combination of some traditional patterns and modern graphic design can more easily reflect the soul of the design of a nation. Nowadays, this is most noticeable in Chinese design, Japanese design, European design, etc. It is done through the extensive use of traditional elements in design directions such as logos, posters, clothing, product packaging, book design, etc, with the purpose of reflecting a nation's cultural semantics and aesthetics but also to become an important symbol of a nation's cultural image. This allows us to understand that graphic design, like art, can become a revealing element of socio-cultural values (philosophical, esthetic, political, economic, historical, sociological). Additionally, it can become a referential support of culture. In short, socio-cultural support with all that can characterize a community, a society and a civilization. Furthermore, graphic design could highlight the particular characteristics of society, of a community, and even enhance it.

How to create a modern African visual design with its particularities, like Chinese, Japanese, Swiss, American design, etc? This is the challenge that many African designers today are trying to meet, but it is also a problem that we would like to answer in this article by taking the Ivory Coast as a field of study.

The purpose of this study is to provide a theoretical method on how to create an African graphic design more precisely Ivorian. We have made a collection of information to describe some key concepts such as culture, cultural identity, creativity, cultural concepts, traditional graphic symbol, graphic design. A logical analysis and a rapprochement between these different concepts have allowed us to find specific relationships between them, which allowed us to lead conclusions concerning these concepts in the context of this study. For a better analysis, the study was divided into three main parts: (i) Culture, Creativity, Cultural Identity; (ii) Exploring the visual language; and (iii) Embodiment of graphic symbols and cultural concepts in graphic design.

\section{Culture, Creativity and Cultural Identity}

\subsection{Culture; A symbol of Cultural Identity}

Culture is the social representation of each nation, including the arts, laws, customs, abilities, and habits of the individuals of these groups, with a strong singularity. Culture has a significant and profound impact on the lives of modern people. According to the British social anthropologist (Tylor, 1871) the concept of culture is:

"That complex body of knowledge, beliefs, art, morals, law, customs and other abilities and habits acquired by man as a member of society". According to this definition, culture is like a peculiarity of man that distinguishes him from others because of the culture or society to which he belongs, because of the type of skill, 
knowledge, the way of practicing his art or practicing his religion, etc. Thus culture is a way of tracing a person's lineage or ancestry (Tetteh, 2013).

According to Banks and McGee (1989), even though, we consider culture as a set of values, symbols interpretations, and perspectives that distinguish people, one from another, it is not only about material objects and other tangible aspects of human societies. People of the same group, of the same culture, generally interpret the meaning of symbols, artifacts, and behaviors in the same or similar ways. At this point, the reality of meaning or significance in this context is linked to that of the culture.

Ivory Coast, like any country has its own culture and history. And the traditional Ivorian culture that comes from the inheritance of the Ivorian culture and which emphasizes the origin of this culture and the objective cultural inheritance transmitted. This traditional culture is thus the whole of the traditional cultural elements.

When we examine content of this Ivorian culture, the main elements that it contains are: woodcarving of masks and statuettes spread all over the country, weaving, pottery, jewelry making, traditional painting ${ }^{1}$, music, and dance (characterized by instruments such as the balafon, the kora, djembe), culinary art and clothing, etc. These are all excellent cultural symbols inherited from our ancestors, over time. These cultural symbols constitute particular characteristics of the culture of the Ivory Coast. They have particularity and stability and allow them to show and recognize the Ivorian culture and its characteristics among other cultures. These elements are part of the cultural identity of this country.

Cultural identity is defined as the physical and emotional attachment that a person has to a particular culture in such a way that it influences choices, behavior, religion, skills, language, and products that are invariably the same as other members of his or her society who identify the person as a fellow human being, as part of the same group.

Collier and Thomas (1988: p. 113) define Cultural identity as

"Identification with and perceived acceptance into a group that has shared systems of symbols and meanings as well as norms/rules for conduct" (Tetteh 2013). This means that the cultural identity of individuals is formed by the attribute and character of the individual that qualifies him/her to be accepted and identified as part of a group or whole. Identity can be associated with language, religion, art forms, beliefs, or skills associated with the manners and processes by which they are manifested by the individual or group (Tetteh, 2013).

(Wieder and Pratt,1990), cited by Tetteh (2013), point out that cultural identities are perceptible in everyday life; members of a culturally identified group employ skills, art forms, symbols, and speak the same or similar languages and understand the same views, ideas, and interpretations-elements from which they can be recognized as being from the same culture.

${ }^{1}$ Korhogo fabrics (Senufo country): strips of approximately $20 \mathrm{~cm}$ in cotton, woven, sewn and then painted. 
Taylor agrees this point of view when he argues that identification is the result of the abilities acquired by man as a member of his society. Furthermore, that culture and cultural identity are concurrent and inseparable (Tylor, 1871).

The will to develop a cultural identity is noted everywhere on the African continent. Since independence, the affirmation of cultural identity constitutes one of the priority objectives that all the African states assigned to themselves on the cultural level. Faced with the need to protect and make effective use of indigenous knowledge that represents a major dimension of the continent's culture and to share this knowledge for the benefit of humanity. This is driven by a desire among African intellectuals to promote a concept of a uniquely African esthetic, developed from a distinctive socio-political point as a new brand image of Africa through a "uniqueness" of African design and culture.

Due to the profound influence of Western design concepts, graphic design in Africa, in general, has never had its concepts and systems design theories, and its cultural foundation is also shallow. This is since most graphic designers have been trained in the modernist form, following functional design philosophy that looks to European and North American perspectives for its creative inspiration, to the detriment of unique local cultural elements in the creation of concepts and design.

This is also mentioned by Casey (2006) who confirms that:

"In graphic design, virtually all models, standards, theory, methodologies, techniques, and technologies derive from the Western world... both in academia and in practice."

For this reason, there are increasing calls for African designers and artists to create work based on graphic symbols, or to integrate traditional symbols into modern design and art.

Lange (2001) asks African designers to "embark on a quest to reflect... diversity, to challenge modernist conventions and produce a graphic design that is essentially local in its components while also being internationally competitive" to change the esthetic standards defined based on Western culture and previously considered "aesthetic standard.

Ricoeur (2007: p. 52) invites to go back to our own origins to face the expansion of the universal culture. He declares to this effect that to confront a foreign culture, one must first have one's own culture and identity.

Modern graphic designers must develop more designs that portray to their nation's style and create stylish designs with new meaning. We have the responsibility and obligation to complete our country's culture in the contemporary graphic design scene, and to promote it. This will bring a breakthrough in modern graphic design in the future. Today, national culture (and the elements it provides) is undoubtedly an important aspect of a nation's development. In the context of design or art, its use allows development of national esthetic specificities; a cultural identity.

"Culture is the source of our progress and creativity, it must be nurtured 
carefully so that it grows and develops" The World Commission for Culture and Development

\subsection{Culture and Creativity}

Generally speaking, creativity is a phenomenon whereby something somehow new and of some value is formed. The object created can be either immaterial (like an idea, a scientific theory, a musical composition, or a joke) or physical (like an invention, printed literary work, or a painting).

In graphic design, creativity is an important element that is constantly sought after; it is, in a way, "the lifeblood of the discipline". A good creative design is full of spirituality and beauty. It can express the thoughts of the designer, and can bring feelings of happiness or anger to audience. Otherwise, it has no "soul", no "power", no "life", and can be unnoticed by the public. To make design powerful, it must have unique ideas and deep concepts, i.e. a good "creativity". Therefore, creativity has an extremely important place in the process of achieving design goals. Only creative designs can attract attention to the market and guide the actions of consumers.

"Culture and creativity", in the context of our study, assume that Africa and particularly Ivory Coast has unique and singular characteristics. These characteristics must be represented in graphic design. To convey the local spirit by using: "the spiritual essence of Africa" (De Jong, 1992: p. 10) in their work, or "an indigenous graphic style" (De Jong, 1992: p. 10) and "a unique African perspective and aesthetic" according Winkler (2001).

This idealism is linked to the local culture, from which the designer must draw all his inspiration and creativity to bring forth into conception singular meanings and visual identities in his graphic design work.

In the same line of concepts, a study called "THE IMPACT OF CULTURE ON CREATIVITY", (made for the European Commission (Directorate General Education and Culture) in June 2009, developed the concept of "creativity" as being "culture-related", which emanates from artistic and cultural productions or activities and which is likely to encourage innovation. This cultural creativity goes beyond the artistic performance or "creative content" that powers broadband networks, computers, and consumer electronics.

The report goes on to state: "This culture-based creativity is linked to the ability of individuals-especially artists-to think imaginatively or metaphorically, to challenge the conventional but also to use the symbolic and the effective to communicate. It can break conventions, "ready-made" thoughts, to allow the emergence of new visions, ideas, or products"

From this point of view, the nature of culture-based creativity (Figure 1) is closely related to the nature of artistic contribution, as expressed in artistic or cultural productions. This spontaneous, intuitive, singular nature, which is the expression of human sensitivity, enriches society. To come into being, "culture-based creativity" depends on: 


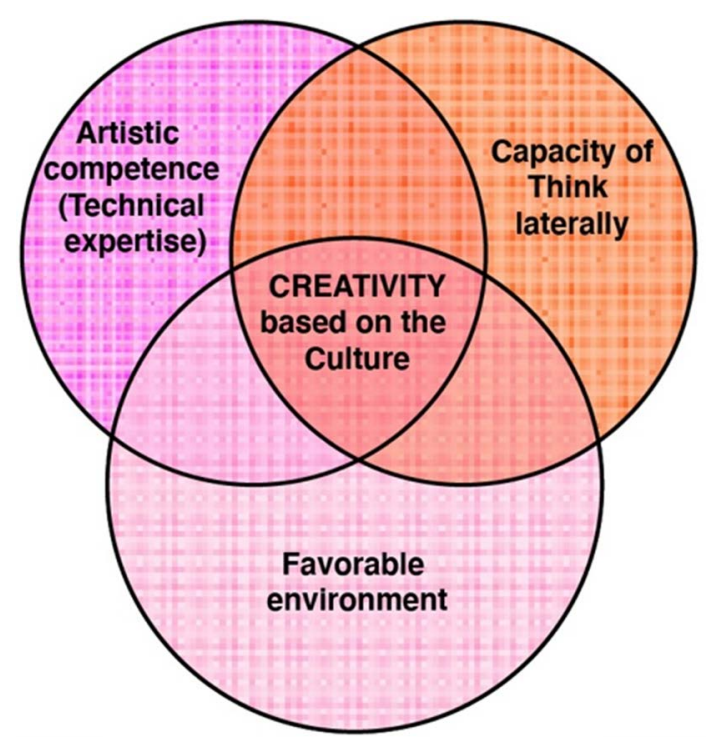

Figure 1. Components of culture-based creativity, source (KEA, 2009).

1) Personal skills (ability to think in a non-linear way, imagination).

2) Echnical skills (often artistic abilities or craftsmanship).

3) A social environment (a social context-including education and learning that encourages and values creativity and an economy that invests in culture and culture-based creativity) (KEA, 2009).

Sternberg and Lubart explain that: "To be creative, an idea must be appropriate, recognized as having social value in some way to a community. They view creativity as the ability to generate new imaginative ideas and create products to solve problems in a community (Sternberg and Lubart 1999).

According to this analysis, "creativity is built on the foundation of culture and uses art and culture for its emergence. Here it is essentially about passion and love or connection with oneself as a human being and member of a culture. This form of creativity embodies many of the characteristics of cultural production.

\subsection{Culture, Creativity, and Innovation}

"Creativity and innovation are normally complimentary activities because creativity generates the basis for innovation, which in its development poses difficulties that must be solved again, together with creativity. It is not possible to conceive of innovation without creative ideas, because these are the starting points".

According to European Commission Report, creativity is a process of interactions and spillover effects between different innovative processes. Innovation cannot be encouraged without recognizing the importance of cultural creativity in the overall process (KEA, 2006).

In summary, innovation results from creativity in the right organizational culture. The right organizational culture provides opportunities through creativity processes (creative techniques) for development of personal and group creativity skills. Innovation occurs when creativity meets the desires and aspirations 
of a particular culture or society.

It is based on a culture where creativity can thrive. For society to accomplish and establish appropriate communication with its people, it must introduce new technological systems based on culture. Culture-based creativity is therefore a key element for companies or public authorities that want to communicate more effectively, challenge conventions, and look for new ways to stand out. It contributes to product innovation, branding, human resource management, and communication. Cultural creativity also needs to develop products and services that meet or create citizens' expectations. Cultural creativity can help in this regard. Thus, it becomes imperative for industry to respond to and create new types of demand that are not based solely on the functionality of a product but rather are rooted in individual and collective aspirations.

According to Sawyer (2006), "a product is creative when experts in the field agree that it is creative, meaning that relevance is defined by social groups and is culturally and historically determined." This thinking by Sawyer offers a consensus definition of creativity.

Csikszentmihalyi (1996), for his part, says "creativity does not occur in people's heads but the interaction between a person's thoughts and a socio-cultural context. It is a systemic rather than an individual phenomenon. Csikszentmihalyi (1996) tries here to define when and how creativity emerges. He argues that culture can help bring certain public services closer to their constituents by incorporating creative media innovations-online discussion on social networking sites allows the public to interact easily with public services. The development of community media and community arts, in general, are good examples of culture-based creativity.

It is also worth reminding that culture plays a considerable role in the innovation of public service delivery, although this aspect remains less considered in public communication innovation. But Holden (2006) emphasizes the importance of culture in the creation of trusted institutions. Indeed, art and culture can benefit from public service delivery and innovation in a variety of ways.

Based on the above analysis of creativity, we can argue that the basis of creativity is not only the creation of something new, but also a combination of new ideas inspired by memories or things one know inspired.

In graphic design, creativity can be seen as a composition of elements in a new way that can communicate with the target audience and is appreciated by the community as valuable information.

We believe that we will have to adapt the vision of creativity. It must be now based on our culture; we must exploit the techniques of culture that can be developed into a unique style of graphic design and allow innovation in the field. In our context, innovating a graphic design style that represents the Ivorian cultural identity will be done if we involve the elements of our culture. We can draw from our rich culture for example by using elements that yesterday inspired and 
influenced world art, for example "Krou masks" (Figure 2) 2 $^{2}$ from Ivory Coast. This part of the question calls to us to explore the local visual language.

\section{Exploring Visual Language}

\subsection{Definition of Visual Language}

By the most general definition, a visual language is a communication system that uses visual elements. Visual language helps the user to perceive and understand visible signs.

Visual language is also, a special form of language, which can cross geographical restrictions, cross-language barriers, and eliminate cultural differences (Gao, 2016).

According to Kepes et al. (1944): "visual language unifies humanity and human wisdom". Visual language can effectively spread knowledge through other means of communication. Visual communication is universal and international. Even people without knowledge can accept it; "it has a dynamic vitality and helps the static thinking of language".

In our contemporary world where information usually comes from visual communication and where the environment visually dependent and evolves toward the graphic, graphic language has become an indispensable visual language in people's lives and plays a very important role in the design of visual communication.

On the other hand, according to (Han, 2019), the connotation of graphic visual language mainly refers to graphic design. Graphic design is an important visual language, spread through visual media. It is intuitive and people can use graphics to generate associations in the process of obtaining information, and eliminating cultural and language barriers. Graphics are symbolic: people perceive graphics visually and display abstract visual images intuitively. Graphics are
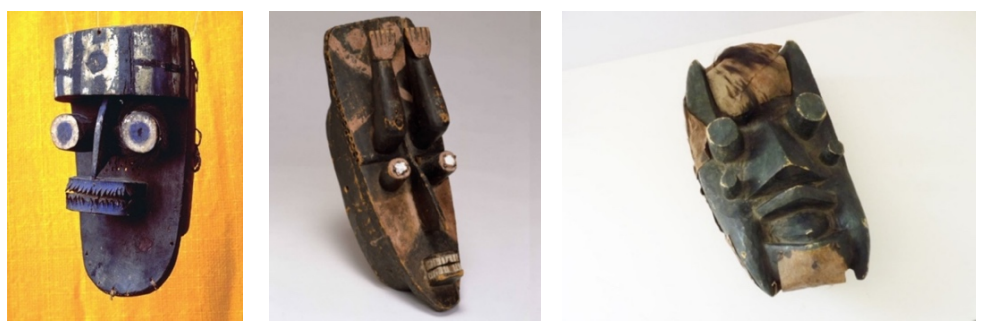

Figure 2. The Grebo masks ${ }^{3}$ of Ivory Coast.

contagious. In visual communication design, the use of graphics makes the design more interesting. The design of abnormal visual images can attract people's

\footnotetext{
${ }^{2}$ The "krou" masks are facial or horizontal masks made of wood, of stylized workmanship, enjoy a good reputation, mainly because of their plastic boldness. Picasso and Braque, in particular, admired the economy of means of a sculptor who built a face by assembling geometric volumes: a cylinder of the forehead and eyes, vertical board of the nose, a rectangle of the mouth, divided by the double line of chevrons representing the teeth (photo. 1). (Verger-Fèvre 1989: 118).

${ }^{3}$ Splendid African mask of ceremony in hard wood. Mask from the Grebo ethnic group in Ivory Coast. Grebo masks are recognizable by their tubular eyes ( 2 or more) and their long nose. These masks attracted the attention of Pablo Picasso, who had his own collection of Grebo masks. He was inspired by them for his painting "Guitar."
} 
attention (Han, 2019).

The visual language of graphic design is a complete specification or symbol system composed of basic visual elements and design principles. The results of graphic design work must depend on human visual analysis. Therefore, visual language is very important for graphic design work.

As an important graphic design language, "visual language" is an important way for designers to convey information. The design process is the process of visual communication. Visual communication is the process of explaining information with vision as a form of cognition. Graphics, colors, and text as components of visual language have different ways of controlling the visual order. So a good graphic design can make visual communication more visible and accentuate the visual effects. For this purpose, the visual language of graphic design should be concise, clear, and easy to understand and remember.

\subsection{The Objective of Exploring the Local Visual Language}

Exploring the visual language based on the above would also mean exploring the whole range of artistic and design forms of visual and graphic expression, which use images and visual elements as the primary means of communicating with public, and which convey to public the design ideas and cultural heritage of the creator through a multitude of image organization methods and esthetic forms. That is to say, all forms of visual art (painting, drawing, engraving, sculpture, photography, video,) and especially all forms of expression and graphic style; poster design, book design, packaging design, web design, motion design, etc, throughout the world, from the West, Europe, Africa and Asia, since visual language is a special form of language that can cross geographical restrictions, cross-language barriers, mix cultural differences, and achieve a satisfying artistic effect.

The interest for us here is to try to know the characteristics of visual language in each culture, even more in our culture; to try to understand how designers and artists work in other parts of the world. To use it as a general knowledge base for our graphic design works.

The exploration of visual language in our context is mostly linked to one main objective in this article; it is the construction of a new visual language. It is the development of a local design language as a brand image. Because Africa and in our specific case the Ivory Coast have characteristics that must be represented in the graphic design. This articulation is also related to the privilege of the "visual" in the discourse of graphic design. To bring out the local or national character of the characteristics of the visual language in the graphic design responding to the traditional aesthetics of the nation and in turn promoting communication of information in the graphic design.

It is in this context that African graphic designers have referred to the need to represent "the spiritual essence of Africa" according to De Jong (1992: p. 10), 
"the indigenous style" according Botha (2009), "an authentically... African style", "a new visual language” according to Unkeless (2008).

To achieve this goal we will need to explore the local African or Ivorian visual language, which represents the characteristics of a singular African design language that local graphic designers should focus on to develop a graphic design that has a singular and unique set of common characteristics with a local spirituality. Explore elements such as graphic symbols, art forms, cultural environment, cultural heritage, cultural concepts and draw the most representative and important elements to insert in our graphic design projects.

\section{Embodiment of Graphic Symbols and Cultural Concepts in Graphic Design}

\subsection{Graphic Symbol and Traditional Ivorian Cultural Symbols}

A graphic symbol is the representation of a concept or an object that characterizes it. Some graphics have a universally known and recognized connotation, others have particular references specific to a culture (Spatio-temporal, professional, etc...).

The symbolic phenomenon is one of the oldest existing social phenomena, associated with men, and it accompanies all the historical processes of human formation. When the activity of consciousness reaches a certain height, the image of the object is registered in the human brain through the activity of thinking or the appearance of cognition to form a conceptual symbol. The symbol is reinforced by life experience, and the images of various objects are fixed, generating cultural symbols (Meng, 2013).

In Ivory Coast for a long time, like everywhere else, graphic symbols have been used as a means of communication, a way to express certain ideas and concepts. These symbols have become over time real cultural concepts of distinction between certain people. For example, the Asante Fulani who already around the nineteenth century began to apply the traditional symbol of Gyaman ${ }^{4}$ on the fabric became the Adinkra on houses on pottery and clothing.

In addition the kente cloth or Kita where each symbol has a cultural meaning. Kente is one of the symbols of the Akan chiefs who remain powerful.

Generally speaking, any symbol that can reflect the regional style and show the traditional cultural characteristics of a region can be called a traditional cultural symbol. Traditional cultural symbols are carriers of traditional culture. On the one hand, they have the characteristics of traditional culture; on the other hand, they can also show unique regional characteristics" (Li \& Zhang, 2017).

Ivorian traditional cultural symbols refer to cultural practices observable throughout the country; in the different ethnic groups of Cote d'Ivoire. They are also habits and customs, ideas and opinions of people, artistic expression; signs of social and cultural belonging in which each Ivorian recognizes himself and ${ }^{4}$ Gyaman, also spelled Jamang, was a medieval Akan people state, located in what is now the Bono region of Ghana and Ivory Coast. 
which constitutes a set of images, forms, and symbols and represents graphic wealth, which would provide a resource of element for modern graphic design.

The traditional Ivorian cultural symbols have progressively evolved into visual symbols representing visual memory and the traditional Ivorian esthetic character, with its unique and singular line form and its symbolic meaning in the process of esthetic evolution little known to all Ivorians, (only the initiates). This progression was made from the indigenous traditions of graphic art that are found in abundance in Côte d'Ivoire, including woodcarving, weaving, pottery, mask making, jewelry making, carving, and painting. This traditional Ivorian art is made primarily for practical purposes, usually concerning religious, health, or village issues. Ivorian artists combine traditional materials - such as wood, ivory, clay, and stone-with folk tales and religious or mythical elements to create their art, which often involves several cultures. This allows them to create unique art.

The Ivorian cultural context (characterized by its diversity of cultural expressions) provides ground for the symbolic meaning of graphic symbols. Knowing that traditional Ivorian graphic symbols, as everywhere else, have their symbolic meaning.

\subsection{The Value of Incorporating Traditional Cultural Symbols into Modern Graphic Design}

The value of incorporating traditional cultural symbols into modern graphic design lies on several levels;

First, the formation of an international style of modern visual design poses a challenge to the design of a traditional national style. The application of traditional cultural symbols is an important way to form a national style of visual design based on local culture. Visual communication is an inextricable part of human history. It has existed for a long time and there has been the need to make marks or leave traces to communicate through signs and symbols rather than the spoken word. In the contemporary world the activity of organizing signs and symbols, or words and images, for public exchange is recognized as graphic design-a specialist area of the broader field of design".

"Visual communication is an inextricable part of human history, which has been practiced for as long as it has been necessary to make marks or leave traces to communicate by signs and symbols rather than by words. In the contemporary world, the activity of organizing signs and symbols, or words and images, for public exchange is recognized as graphic design-a specialized area of the larger field of design" (Aynsley, 2001). This statement by Jeremy Aynsley (2001) shows us that the use of graphic symbols as a means of communication is not new (it is as old as the dawn of time) and is not limited to a single person or a particular culture. This form of communication has developed over time to become a recognized discipline that plays an important role today and which affects its visual character in almost all societies and cultures in different ways with 
particular cultural connotations.

The meaning of traditional cultural symbols in modern visual design, on the one hand, develops their traditional meaning through new forms and, on the other hand, transforms and develops the original figures into the traditional meaning. The resulting "meaningful forms" necessarily contain the ideas and emotions of the designer, which are integrated into the ideas of the subject of the design, are perceived by the viewer, the ideas give life to the form, and, therefore, the form becomes active in the sense of representation. It is also a way to bring together tradition and modernity in the sense of innovation.

It is conducive to the protection of the traditional Ivorian cultural heritage. With globalization and the cultural invasion of Western powers in recent years, our traditional culture has gradually declined. Due to the lack of strong African cultural policies, one can see the gradual withdrawal of traditional culture from the lives of the people. The West is becoming a reference point for the younger generation. This fact is also perceptible in "African design" where African designers are more inspired by Western design systems to the detriment of their own culture. The introduction of traditional cultural symbols into modern graphic design is conducive to the protection and legacy of traditional culture. It will put the traditional culture back into people's daily life and let it rejuvenate. The best protection is not to place it in a museum, but to make it live in a new artistic creation. It is only by constantly innovating and developing in the works that we could effectively protect the traditional cultural symbols.

Furthermore, the development or extension of traditional graphic symbols into graphic design could allow for the creation of an Ivorian-style design with a distinctive edge. By exploring elements such as traditional art that best embodies the country's traditional esthetic thoughts and national cultural characteristics. Because of the particularity of materials and tools such as the forms of Ivorian sculptures in Ivorian art, which has a unique esthetic, different from the esthetic of Western art.

\subsection{Application of Traditional Cultural Symbols to Modern Graphic Design}

How to create an "Ivorian style" graphic design; by highlighting Ivorian characteristics in modern design, while enriching this discipline. In the following lines, we will state some important points in order to create these Ivorian particularities in graphic design.

\section{1) The application of traditional graphic symbols in graphic design}

Graphic symbols, as we have said earlier, have been used as a means of communication, a means of expressing certain ideas and concepts, with their specific and deep symbolic meaning. Some often express positive connotations and have a considerable impact on a certain population of Ivory Coast. The fusion of graphic symbols and modern elements not only reflects the level of an esthetic connotation of traditional culture but also meets the esthetic requirements of 
modern public. For example, in the Akan culture, Adinkra symbols were once used by clans as a mark of wealth. Adinkra symbols express various themes related to history, beliefs, and philosophy of the Assante (Ashanti people of Côte d'Ivoire and Ghana). Most of them have a rich proverbial meaning because proverbs play an important role in the Assante culture where the use of proverbs is considered a mark of wisdom that also represents traditional good omens that could be used in the design of modern visual communication. This is the case for example of the symbol Adinkra "AKOMA" (Figure 3) which is literally translated as "Heart" and which calls for Patience and Tolerance or the symbol Denkyem (Figure 4) which is the symbol of the crocodile and which means Adaptability, Cleverness and the symbol " $A D W O$ " (Figure 5) literally Calmness and which means and Peace, tranquility, quiet.

\section{2) The application of elements of the traditional art of Cote d'Ivoire.}

Art considered the essence of a country's culture, has extremely high esthetic characteristics in terms of modeling, coloring, and artistic design. In Côte d'Ivoire, we have traditional weaving, Korhogo painting, and pottery. They all represent a unique characteristic of Ivorian culture. These art forms are present in all cultural regions of the country in distinct ways.

Firstly, the Baulé, Dioula, and Senufo ethnic groups are distinguished in art of weaving, particularly the Baulé people who weave the Baulé loincloth (Figure 6) in a town called Bomizambo (about $30 \mathrm{~km}$ north of Yamoussoukro). The loincloth Boulé is one of the most beautiful African fabrics. The Bomizambo weavers are true artists who give life to the Ivorian craft heritage.

The Senufo and Dioula, people from the north of the country, also excel in this art (Figure 7) and (Figure 8). Originally, the woven patterns were linked to

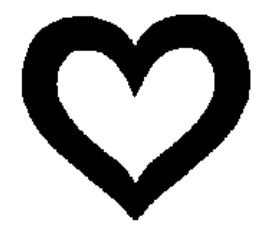

Figure 3. AKOMA symbol.

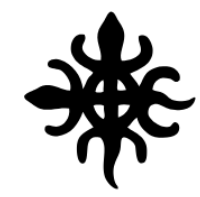

Figure 4. DENKYEM symbol.

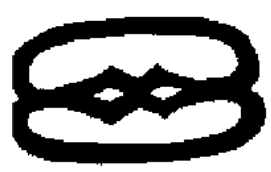

Figure 5. ADWO symbol. 
the use of the clothes according to the events: initiation parties, weddings etc. the shrouds always remained white. These patterns have evocative names such as "Panther's teeth", "cowries" or "pineapple skin".

Then the Baulé and especially the Senufo ethnic groups are renowned for their painting on cloth called "Korhogo cloth" on panels of unbleached cloth, the craftsman draws symbolic animals, accompanied by geometric patterns.

Korhogo cloth (Figure 9) is the sacred essence of traditions and cultural symbols important to the Senufo. Before an artist makes his canvas, a fetishist must transmit to him the subjects that he will treat on the canvas. The painter executes his work after receiving the message but retains complete creative freedom over the subject. The result is always unique, even if we find the same
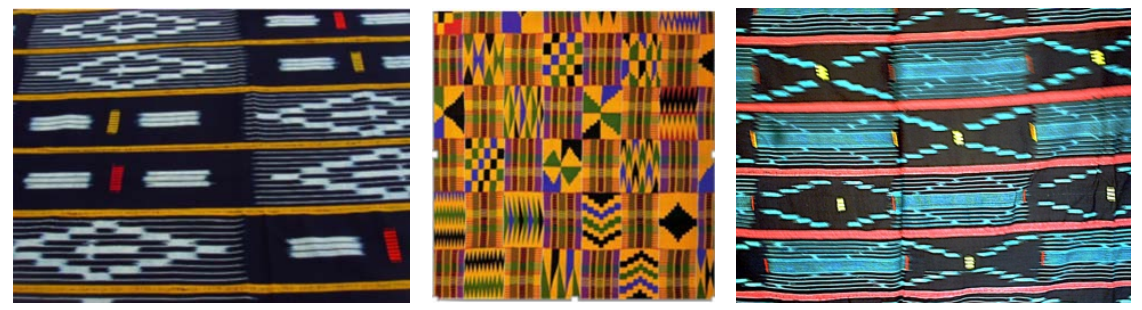

Figure 6. Loincloths made among the Baoulés, Akan ethnic group in Ivory Coast in West Africa.

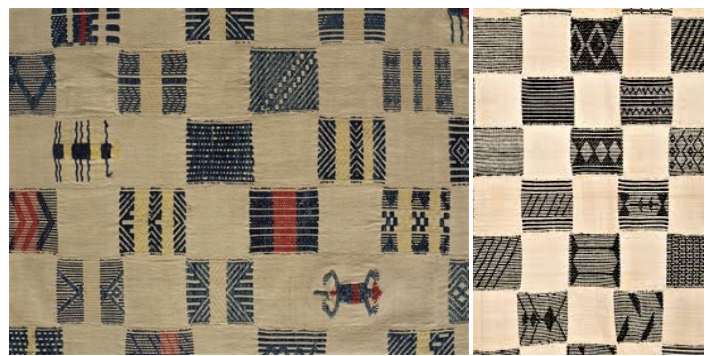

Figure 7. Dioula Loincloths.
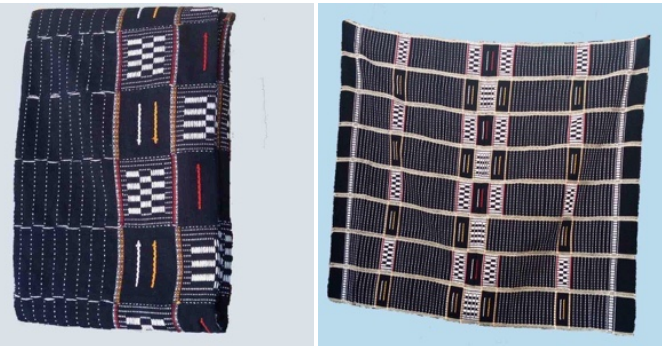

Figure 8. Senoufo Loincloths.
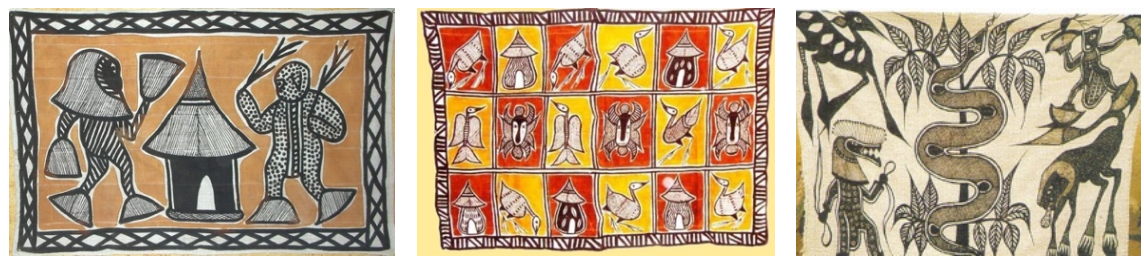

Figure 9. Korhogo canvases'; Senufo paintings. 
symbols from canvas to canvas.

Then, the Malinke ethnic groups in the west and north-west are masters in art of pottery, although this art is practiced by all ethnic groups, pottery is very present among the Malinke. Jars, canaries, and vases are handmade (Figure 10) and heated over the fire. The pottery of Katiola is the most renowned in the country.

The fame of these three crafts is due to their esthetic quality, appreciated not only by the local population but also by foreign tourists who consider them as real works of art.

In modern graphic design, we can combine the artistic ideas and symbolic elements of the Senufo cloth (Korhogo cloth), and the elements of woven loincloth and pottery that are present throughout the territory, and integrate them into the content of modern graphic design. The expansion and enrichment of these media plays an important role. The integration of the symbols of woven loincloths and elements of painting on canvas and pottery is not only conducive to innovation but also to the development of modern graphic design in Ivory Coast and even internationally.

On the other hand, the combination of the unique spiritual significance of these three elements (of weaving, pottery, and painting of Korhogo) in the modern graphic design will promote the fusion between the mystery of traditional sometimes mystical reality and the modernity in work, and this can achieve the perfect combination of the essence of the national traditional culture of Côte d'Ivoire and the modern aesthetics.

\section{3) The application of elements of traditional color symbols.}

Traditional color itself has strong symbolic, diversified and allegorical characteristics, it is a nutritious element that should be absorbed into modern graphic design and can bring people different visual feelings (Li \& Zhang, 2017). Indeed, color plays a leading role in design, and its status in modern design is becoming more and more important in the design of visual language. The organization of color language in graphic design requires a variety of factors to

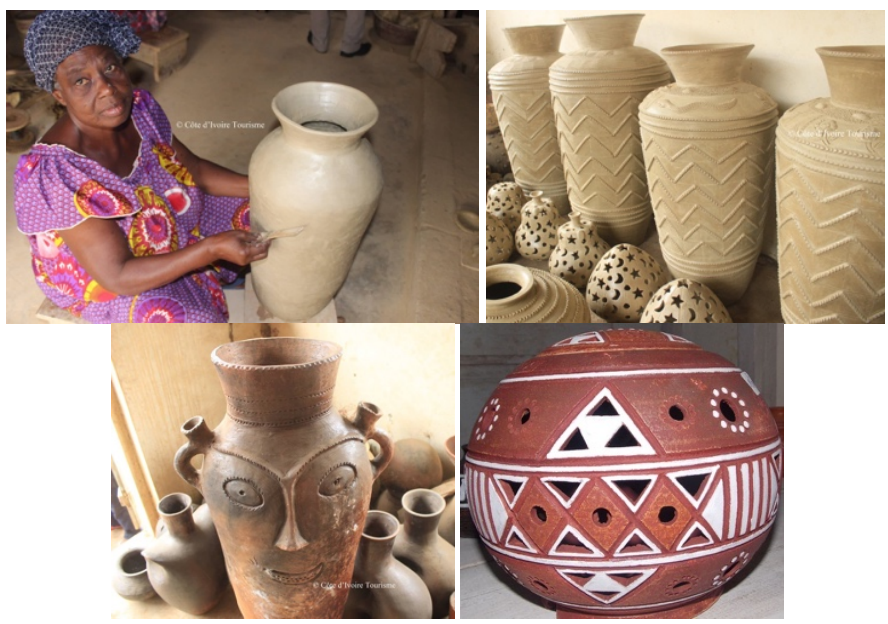

Figure 10. Different pottery from Côte d'Ivoire. 
achieve a reasonable visual effect and form a harmonious color rhythm. In contrast to the effect of various color factors, the use of color characteristics and designer's thinking to achieve a variety of color combinations is the basic policy to deal with color.

Color is an important part of the development of a nation and an important manifestation of a country's civilization (Li \& Zhang, 2017).

We also know that the way we perceive and interpret colors changes in different cultural contexts. Generally in African culture, traditional colors have strong symbolic meanings and also reflect strong national sensitivities.

According to Gbakui (2018):

"Three colors are essentially common to the peoples of sub-Saharan Africa.

They are: black, red and white." "This is attested to by Senghor in his writ-

ing on The Negro-African esthetic when he states that "the figures are

painted with traditional colors of black Africa: white, black, red” (Senghor,

1956).

Besides these three «universal »colors, there are some other colors on the palette of sub-Saharan color. These include yellow ocher, the color of the earth and quite common in forest and savannah areas, blue and green, which are rare (Seidou, 2007). But they are found in Akan fabrics also called Kente.

As shown in (Table 1) below, colors take on a different meaning from one group to another. Traditional colors, with their symbolic characteristics, diversity, and connotation, must be taken into account in modern graphic design because they can bring different visual sensations. The traditional symbolism of colors constitutes a significant body of traditional knowledge. The rational use of traditional color elements will bring design closer to people's lives and produce rich national spiritual connotations in modern graphic design. From the perspective of innovation, these colors can be used juxtaposed with new colors to show innovation while keeping the local spiritual characteristics in the graphic design.

Table 1. Symbolic decoding of the main patterns and colors in Akan, Dan and Senufo loincloths) (Gbakui, 2018).

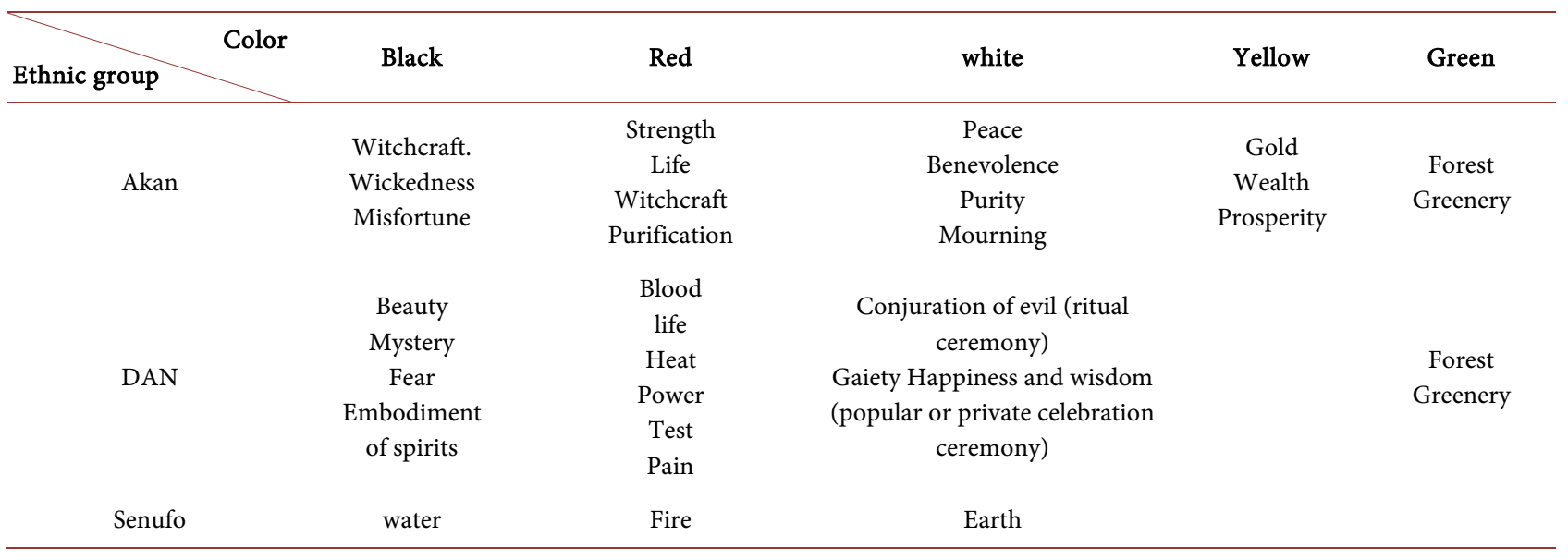


In the application of traditional graphic symbols, a distinction must be made between direct use of traditional graphic symbols and indirect use of traditional graphic symbols:

\section{4) Direct use of traditional graphic symbols.}

Here it is a question of directly applying the original traditional symbols to the graphic design. These symbols can be directly expressed in the design. In Côte d'Ivoire, in addition to the Adinkra graphic symbols, there are many excellent designs and motifs presented in the form of traditional graphic symbols, which are seen as the identity mark of a population or a village. Symbols like the Bogolan symbols (Figure 12), and the symbols on Akan gold weights (Figure 11) can also be used in the graphic design, which will bring a sense of intimacy from the Ivorians toward these symbols.

We also know that writing or script is also a direct symbol because some of the writings we use today come from symbols that were used thousands of years ago. In the case of Cote d'Ivoire, we have the Bété script of Ivory Coast. The application of the (Bruly Brouabré, 1919-2014). ${ }^{5}$ Bété script (Figure 13) can easily convey local cultural information or concepts and create originality. The use of the Bété script in graphic design.

Indeed languages and writing are important means of conveying information, as the text also has graphic characteristics, Lupton (1996) rightly states that:

"a typeface and the way it is used can declare the cultural identity of a body or that of a designer. The typeface is a fundamental form of writing and printing that can make graphic images more meaningful and attractive. Fonts can represent and express various meanings to audiences with different appearances of shapes"

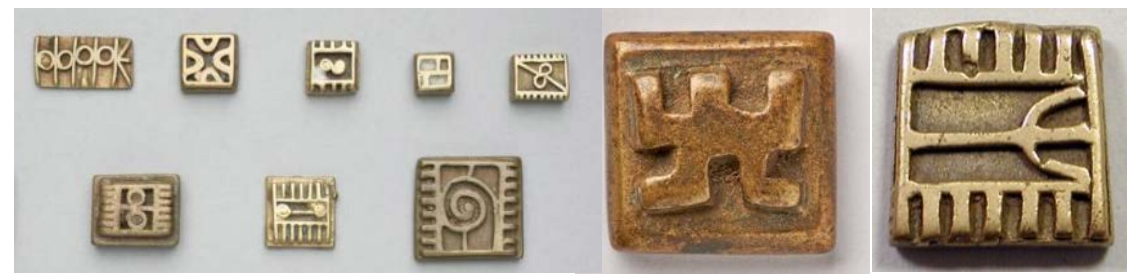

Figure 11. Akan Gold weights symbol @ Collection at the Dida.
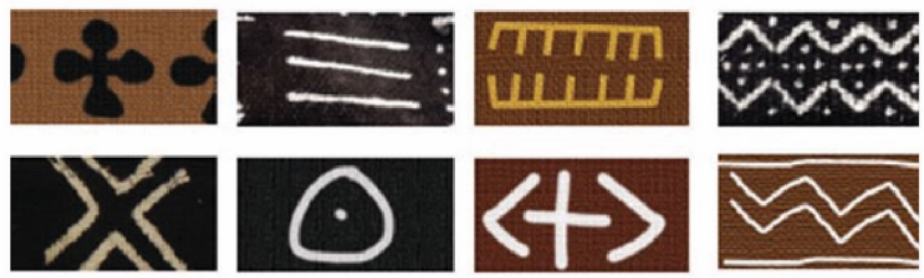

Figure 12. Bogolan loincloth symbol.

${ }^{5}$ Frédéric Bruly Bouabré, born in 1919 in Zépréguhé, circle of Daloa, Ivory Coast. He died on January 8, 2014,he created a 448-letter, universal Bété syllabary,(bété script) which he used to transcribe the oral tradition of his people, the Bétés (from Ivory Coast). 

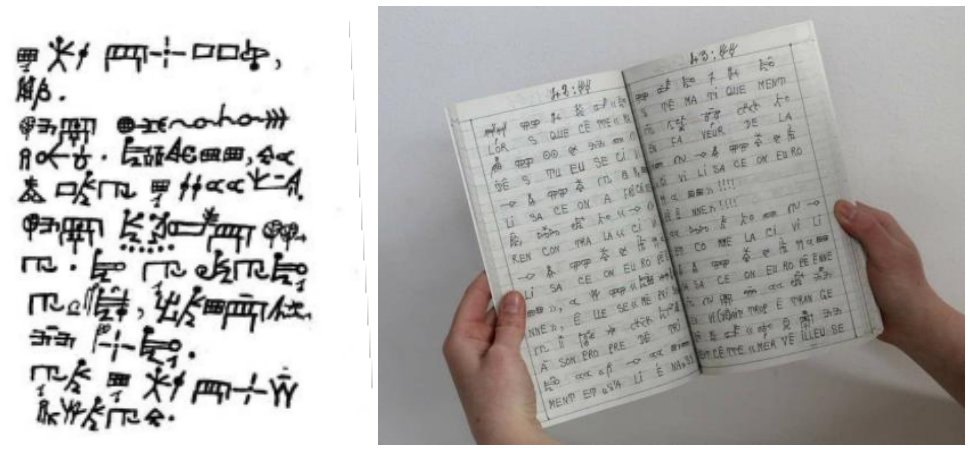

Figure 13. Bété script.

\section{5) Indirect use of traditional graphic symbols.}

The symbols used in modern graphic design are usually abstract and metaphorical, with emotional and life-like images. Here the symbols are applied indirectly. The use of these traditional symbols is usually not to express the symbol itself but to express the special meaning of the symbol in an indirect form. It is up to the designers to intelligently combine modern and traditional elements by learning how to correctly change traditional cultural symbols based on the understanding of connotative characteristics of traditional graphics, to merge traditional and modern characteristics, to achieve a new vitality of traditional graphics symbols.

A designer can use the rules of formal beauty as a guide and use different artistic expressions to organize symbols with the same appearance characteristics and combine different symbols to present different beauty of rhythm and pace (Yuan, 2019).

The indirect use of traditional graphic symbols also alludes to the reconstruction and recreation of elements of traditional symbols.

According to Yuan Yiquan (袁泉), traditional graphic symbols are composed and use various elements such as points, lines, and surfaces that constitute traditional graphic symbols, to break them down and reconstruct them after analyzing the rules of using these elements. The combination of the different elements of these symbols between them can form new elements of design symbols that can bring different effects of visual art, conducive to innovation and development of a modern graphic design.

In addition to the elements already listed, there is also an important element and particularly representative of the Ivorian culture:

6) The use of elements of masks and geometric figures.

Because of the geographical and cultural areas that make it up and the various exchanges that history has allowed, the Ivory Coast occupies a place of choice in the sculpture of African masks.

Indeed the culture of the mask is represented, in each ethnic group, in the north at the Senoufo ethnic group, we find stylistic forms of the Bambara and Dogon countries (Figure 14). While in the West with Dan and the Wế, we find ${ }^{6}$ The Wê, sometimes called the Krahn or Guere, are an indigenous African people that inhabit areas in eastern Liberia and western Côte d'Ivoire. 
masks with naturalistic and cubist constructions characteristic of this area (Figure 16), (Figure 17). This influence developed from West to East, by the Gouro, close relatives of the Dan, and by the Niaboua, Bakoué, Kroumen, Néyo, Bété, and Godié, culturally related to the Wê.

Finally, the sculpture of the Baulé masks (Figure 15) participates at the same time in the artistic techniques of the Atlantic area of the East (Akan, Adja Yoruba) and of the Senufo and Gouro styles, thus proceeding to a synthesis of the conceptions of the West, the East and the North of our sub-region of West Africa.

The result for the Ivory Coast is an imposing cultural richness that makes it, in West Africa, one of the privileged regions of the mask.

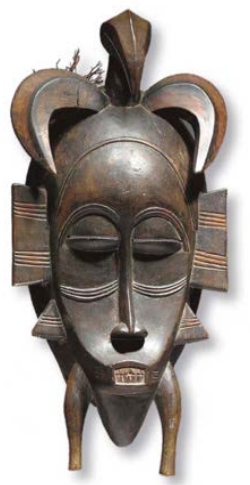

Figure 14. Senoufo mask, Kpelie.

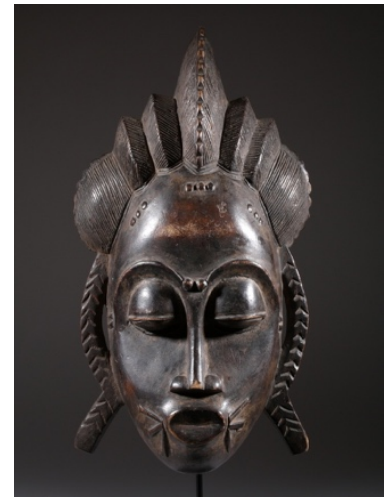

Figure 15. Baoulé mask, Kpelie.

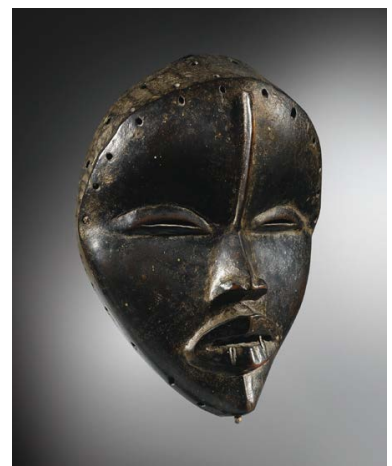

Figure 16. Dan mask. 


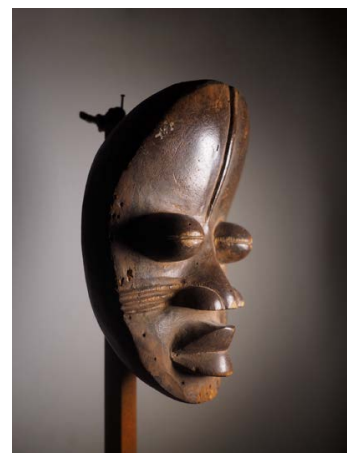

Figure 17. Wê mask.

Ivorian masks occupy an important place in the traditional culture of Cote d'Ivoire, including many symbols and its geometric figures applicable to modern graphic design. This will be the expression of design ideas and visual design tastes reflecting the cultural image and traditional cultural value of Cote d'Ivoire.

The combination of traditional cultural symbols with modern graphic design not only offers a new way to protect the heritage of traditional cultural symbols, make them known, emphasize and reactivate their use in everyday life but also promotes new graphic creativity (a new design) of these Ivorian symbols.

However, the symbolism of the "form" of the traditional graphic symbol in the cultural context of Côte d'Ivoire must be taken into account for a better understanding and use of these symbols.

Designers should use the deep Ivory Coast cultural philosophy as a background, and continue to seek new and deeper design ideas while adding and combining modern design theories (Western, Chinese,) to refine design methods suitable for modern life, to revive the traditional cultural symbols. This will finally enrich the elements of national and international design by perpetuating the traditional culture of our country.

\section{Conclusion}

The importance of encouraging and protecting all innovative practices based on a people's culture cannot be overemphasized, as these practices are integral to maintaining the cultural identity of the people. As culture is the source of our progress and creativity, it must be carefully nurtured so that it grows and develops. Therefore, the absence of cultural creativity can undermine the renewal and development of a nation. That is why artistic contributions or productions are to be encouraged to enrich society.

The innovation of a graphic design based in Africa and Ivory Coast must be treated with importance, because graphic design as an effective communication tool has power to preserve, reflect, promote and publicize our culture. This is done by integrating it into the concepts of modern design, traditional cultural elements such as elements of traditional symbols, traditional colors, elements of masks and geometric figures, by development of symbol of continuous graphic design. 
In this article, we have attempted through an analysis to demonstrate how to apply traditional Ivorian symbols to modern graphic design. Our final observation is that traditional cultural symbols and their derivatives; graphic symbols are the embodiment of material and spiritual cultural phenomena such as thoughts, customs, arts, and ways of life that are fruit of a nation's history. To this end, graphic symbols constitute a great wealth of semiotic, graphic, and morphological elements, which make them applicable in all the different types of modern design. The knowledge of these cultural symbols and Ivorian graphic symbols and their use can add a depth of cultural resonance and adequacy rarely found in contemporary graphic design.

For this reason, the Ivorian designer or the designer, in general, must know well the meaning of the Ivorian characters and graphic symbols, relying on the philosophy and cultural connotations of the Ivory Coast as a background, while continuing the search for new and deeper design ideas, while adding and combining the theories of modern design (Western, Chinese, etc) to refine the design methods adapted to modern life, to revive the traditional cultural symbols. This will, as we said earlier, enrich the elements of national and international design by perpetuating the traditional culture of our country.

\section{Conflicts of Interest}

The authors declare no conflicts of interest regarding the publication of this paper.

\section{References}

Aynsley, J. (2001). Century of Graphic Design. London: Octopus Publishing Group Ltd.

Banks, J. A., \& McGee, C. A. (1989). Multicultural Education. Needham Heights, MA: Allyn \& Bacon.

Botha, N. (2009). The Indigenous Style. Design Indaba. http://www.designindaba.com/news/indigenous-style

Casey, P. (2006). Towards a Meeting of Graphic Design and Indigenous Knowledge. DEFSA-Conference 2006 Research Paper.

Collier, M. J., \& Thomas, M. (1988). Cultural Identity: An Interpretive Perspective. Thousand Oaks, CA: Sage.

Csikszentmihalyi, M. (1996). Flow and the Psychology of Discovery and Invention. Harper: Perennial.

De Jong, E. (1992). Blue Sky: A New Creative Spirit in South African Design? Image \& Text, No. 1, 1 April, 10-11. https://doi.org/10.1080/10118063.1992.9723870

Gao, L. N. (2016). Exploring the Visual Language of Design. Art Observation, 12, $72-73$.

Gbakui, T. (2008). Étude sur la culture du pagne en Côte d'Ivoire: Motifs, dénominations et leurs implications chez les Akan, Dan et Sénoufo. Master Etudes Coréennes, Abidjan-Côte d'Ivoire.

https://etudescoreennes-abidjan.blogspot.com/2018/02/etude-sur-la-culture-du-pagneen-cote.html

Han, X. (2019). Study on the Expression of Graphic Language in Visual Communication Design. Art Science and Technology, 8. 
Holden, J. (2006). Cultural Value and the Crisis of Legitimacy. London: Demos. https://en.wikipedia.org/wiki/Creativity

KEA European Affairs (2006). The Economy of Culture in Europe. Brussels: European Commission, DG Education and Culture.

Kepes, G., Giedion, S., \& Hayakawa, S. I. (1944). Language of Vision. ETC: A Review of General Semantics, 2, 181-183.

KEA (2009). The Impact of Culture on Creativity.

Lange, J. (2001). Local Is Lekker: The South African Design Stew.

Li, Q. H., \& Zhang, G. B. (2017). The Application of Traditional Cultural Symbols in Modern Visual Communication Design. Art World, 6, 72.

Lupton, E. (1996). Mixing Messages: Contemporary Graphic Design in America. London: Thames \& Hudson Ltd.

Meng, S. J. (2013). Imaginative Expression of Traditional Cultural Symbols in Modern Visual Design. Art Sea, 6, 131-131, 132.

Ricoeur, P. (2007). Universal Civilization and National Cultures. In Architectural Regionalism (p. 52). New York: Princeton Architectural Press.

Sawyer, R. K. (2006). Explaining Creativity: The Science of Human Innovation. Oxford: University Press.

Sternberg, R. J., \& Lubart, T. I. (1999). The Concept of Creativity: Prospects and Paradigms. In R. J. Sternberg (Ed.), Handbook of Creativity (pp. 3-15). Cambridge: Cambridge University Press. https://doi.org/10.1017/CBO9780511807916.003

Tetteh, S. (2013). Traditional African Art Forms: Sources of Inspiration for Graphic Design.

Tylor, E. B. (1871). Primitive Culture: Research into the Development of Mythology, Philosophy, Religion, Art, and Custom (Volume 1, p. 1). London: John Murray.

Unkeless, G. (2008). SA: The US of Africa.

http://www.designindaba.com/news/sa-us-africa

Winkler, M. (2001). Design Indaba: Mission Critical. Design Indaba Magazine. http://www.designindaba.com/news/design-indaba-mission-critical

Yuan, Q. (2019). Exploration and Application of Traditional Symbol Elements in Graphic Design. Theatre House, 314, 154.

Wieder, D. and Pratt, C. (1990). On Being a Recognizable Indian among INDIANS. New Jersey: Lawrence Erlbaum Associates. 